\title{
Loss of beclin 1 expression in ovarian cancer: A potential biomarker for predicting unfavorable outcomes
}

\author{
TOSHIKO MINAMOTO $^{1}$, KENTARO NAKAYAMA $^{1}$, KOHEI NAKAMURA $^{1}$, HIROSHI KATAGIRI $^{1}$, \\ RAZIA SULTANA $^{1}$, TOMOKA ISHIBASHI ${ }^{1}$, MASAKO ISHIKAWA ${ }^{1}$, HITOMI YAMASHITA $^{1}$, KAORI SANUKI $^{1}$, \\ KOUJI IIDA ${ }^{1}$, SATORU NAKAYAMA ${ }^{2}$, YOSHIRO OTSUKI ${ }^{3}$, NORIYUKI ISHIKAWA ${ }^{4}$ and SATORU KYO ${ }^{1}$ \\ ${ }^{1}$ Department of Obstetrics and Gynecology, Shimane University School of Medicine, \\ Izumo, Shimane 6938501; Departments of ${ }^{2}$ Obstetrics and Gynecology and ${ }^{3}$ Pathology, \\ Seirei Hamamatsu General Hospital, Hamamatsu, Shizuoka 4308558; ${ }^{4}$ Department of \\ Organ Pathology, Shimane University School of Medicine, Izumo, Shimane 6938501, Japan
}

Received May 1, 2016; Accepted June 29, 2017

DOI: $10.3892 / \mathrm{ol} .2017 .7379$

\begin{abstract}
The clinicopathological significance and prognostic value of the expression of proteins associated with autophagy, beclin 1 (BECN1), 1A/1B-light chain 3 (LC3) and high mobility group box-1 protein (HMGB-1), were investigated in patients with ovarian carcinoma, receiving combination chemotherapy with a platinum agent and a taxane. Immunohistochemical staining was performed for autophagy-associated proteins in tumor tissues from 141 patients with ovarian carcinoma. Clinical data were collected retrospectively by reviewing medical charts, and the association between protein expression, clinicopathological features and survival was investigated. Amongst 141 ovarian carcinoma samples, the loss of BECN1, LC3, and HMGB-1 expression was identified in 59 (41.8\%), 35 (24.8\%), and 66 (46.8\%) samples, respectively. Clinicopathological factors were not significantly associated with the loss of BECN1 expression. However, significant associations were demonstrated between the expression of BECN1, LC3, and HMGB-1. In addition, loss of BECN1 expression demonstrated a significant association with poor progression-free and poor overall survival. Multivariate analysis demonstrated that loss of BECN1 expression and postoperative residual tumor were significant independent predictors of poor progression-free survival and poor overall survival. These results indicated that loss of BECN1 expression in ovarian carcinoma is a negative prognosticator in patients receiving platinum-based chemotherapy. Assessment of BECN1 expression may be useful for predicting an unfavorable response to platinum-based chemotherapy in ovarian carcinoma.
\end{abstract}

Correspondence to: Dr Kentaro Nakayama, Department of Obstetrics and Gynecology, Shimane University School of Medicine, 89-1 Enyacho, Izumo, Shimane 6938501, Japan

E-mail:kn88@med.shimane-u.ac.jp

Key words: ovarian carcinoma, beclin 1, survival, platinum, taxane

\section{Introduction}

The number of patients with newly diagnosed ovarian cancer has gradually decreased, however, the 5-year survival rate of this disease is still $40 \%$, which remains a lethal gynecological malignancy (1). In $\sim 60 \%$ of patients with ovarian cancer, the tumor has spread beyond the ovaries at diagnosis, and these patients require surgery combined with chemotherapy (2). Platinum-taxane combination chemotherapy is the current gold standard treatment for ovarian cancer. However, irrespective of the initial tumor response, long-term survival is poor, particularly in patients with advanced disease at the point of diagnosis. Relapse and non-response to initial chemotherapy are thought to be associated with tumor drug resistance (3). Recently, the resistance of ovarian cancer to chemotherapy agents has been studied extensively and multiple targets for novel treatments have been proposed (4). Chemotherapy treatment is often aimed at inducing tumor cell apoptosis, and research has been focused towards either the activation of apoptosis or lowering the apoptotic threshold via the administration of cytotoxic drugs (5).

Evasion of apoptosis is a hallmark of cancer, leading to the failure of chemotherapy treatment and subsequent tumor progression (6). Autophagy, an alternative caspase-independent cell death program, is a highly conserved process of degradation, by which cytoplasmic components are sequestered in lysosomal vesicles and recycled to provide energy $(7,8)$. In addition, autophagy is induced by various stresses, including chemotherapy $(9,10)$. The autophagy-associated genes which have currently been identified include $\sim 30$ yeast genes and 16 human homologues, among which beclin 1 (BECN1), 1A/1B-light chain 3 (LC3), and high mobility group box-1 protein (HMGB-1) are important for mammalian autophagy (11-14). The involvement of autophagy in chemoresistance in the progression of ovarian cancer and the underlying molecular mechanisms involved remain unclear. To the best of our knowledge, the clinicopathological significance of the expression of key autophagy-associated molecules in ovarian cancer, including BECN1, LC3, and HMGB-1, has not yet been established. 
Therefore, the aim of the present study was to clarify the relevance of the expression of these autophagy-associated proteins to the prognosis of ovarian cancer.

\section{Materials and methods}

According to previous studies, the positive rates of Beclin 1 were significantly higher in ovarian cancer than in benign ovarian tumor or normal ovarian tissue (15). Ovarian tissue samples were submerged in $10 \%$ formalin for 24 to $48 \mathrm{~h}$ at room temperature. Paraffin-embedded tissue samples from 141 ovarian cancers were analyzed, including samples of 34 serous carcinomas, 20 mucinous carcinomas, 60 clear cell carcinomas and 27 endometrioid carcinomas. Tumor tissues from female patients were obtained from the Department of Obstetrics and Gynecology at Shimane University Hospital (Izumo, Japan), and the Department of Obstetrics and Gynecology at Seirei Hamamatsu General Hospital (Hamamatsu, Japan), all of whom underwent surgery at this hospital between January 1998 and December 2008. All patients with ovarian cancer were aged from 46 to 76 years (median, 61 years). Diagnosis was based on the conventional examination of hematoxylin-eosin stained sections. Tumors were classified according to the World Health Organization classification and staging was performed according to the International Federation of Gynecology and Obstetrics (FIGO) classification (16). All patients underwent primary cytoreductive surgery and received 6-12 cycles of adjuvant platinum-taxane combination chemotherapy [carboplatin (CBDCA, AUC 5) with paclitaxel; $175 \mathrm{mg} / \mathrm{m}^{2}$ or docetaxel; $70 \mathrm{mg} / \mathrm{m}^{2}$ ]. The Institutional Review Board of Shimane University Hospital and Seirei Hamamatsu General Hospital approved the examination of tumor tissues and the research was conducted according to the Declaration of Helsinki. Written informed consent was obtained from all of the subjects. Tumor cores ( $3 \mathrm{~mm}$ in diameter) from the paraffin-embedded blocks were organized on tissue microarrays (TMAs). Tumor cores were selected by a gynecologic oncologist (K.N, Shimane University, Shimane, Japan) and a pathology technician (K.I, Shimane University), and criteria were based on a review of the hematoxylin-eosin stained slides.

Immunohistochemistry (IHC). The expression of BECN1, LC3, and HMGB-1 proteins were assessed by IHC staining performed on $4 \mu \mathrm{m}$ tissue sections from core tumor biopsies ( $3 \mathrm{~mm}$ in diameter). TMA sections were incubated in sodium citrate buffer ( $\mathrm{pH} \mathrm{7.0)}$ ) for $30 \mathrm{~min}$ at $97^{\circ}$ to perform antigen retrieval. Briefly, tissue sections were dewaxed in xylene for $10 \mathrm{~min}$ at $20^{\circ} \mathrm{C}$, rehydrated in $70 \%$ graded ethanol and $100 \%$ ethanol, washed in PBS ( $\mathrm{pH} \mathrm{7.25)} \mathrm{for} 5 \mathrm{~min}$ and quenched in peroxidase-blocking reagent for $5 \mathrm{~min}$ at $20^{\circ} \mathrm{C}$ to remove endogenous peroxidase activity. TMA sections were incubated overnight at $4^{\circ} \mathrm{C}$ with mouse monoclonal primary antibodies against BECN1 (Cat. no. NB110-55556; dilution, 1:100; Novus Biologicals, LLC Littleton, CO, USA), LC3 (Cat. no. NB100-2220; dilution, 1:400; Novus Biologicals, LLC), and HMGB-1 (Cat. no. 6893; dilution, 1:400; Cell Signaling Technology, Inc., Danvers, MA, USA). The following day, slides were washed three times with PBS prior to the detection
Table I. Associations between BECN1 expression and clinicopathological factors in patients with ovarian cancer.

BECN1 expression

Factors

Patients Negative Positive P-value

\begin{tabular}{lrrrr}
\hline FIGO stage & & & & \\
III, IV & 61 & 31 & 30 & 0.0592 \\
I, II & 80 & 28 & 52 & \\
Grade & & & & \\
G2, G3 & 124 & 53 & 71 & 0.3798 \\
G1 & 16 & 5 & 11 & \\
Histology & & & & \\
$\quad$ Serous & 34 & 19 & 15 & 0.0568 \\
Others & 107 & 40 & 67 & \\
Age, years & & & & \\
$\geq 60$ & 59 & 27 & 32 & 0.4236 \\
$\quad<60$ & 82 & 32 & 50 & \\
Residual tumor, cm & & & & \\
$\geq 1$ & 55 & 25 & 30 & 0.487 \\
$\quad<1$ & 86 & 34 & 52 & \\
LC3 expression & & & & \\
$\quad$ Negative & 35 & 25 & 10 & $<0.0001^{\mathrm{a}}$ \\
Positive & 106 & 34 & 72 & \\
HMGB-1 expression & & & & \\
Negative & 66 & 41 & 25 & $<0.0001^{\mathrm{a}}$ \\
Positive & 75 & 18 & 57 & \\
\hline
\end{tabular}

${ }^{\mathrm{a}} \mathrm{P}<0.05$. BECN1, beclin1; FIGO, International Federation of Gynecology and Obstetrics; LC3, 1A/1B-light chain 3; HMGB-1, high mobility group box-1 protein.

of antigens using the two-step DAKO EnVision+ Peroxidase System (DAKO; Agilent Technologies, Inc., Santa Clara, CA, USA), according to the manufacturer's protocol at room temperature for $30 \mathrm{~min}$. After rinsing with PBS, the sections were incubated for $5 \mathrm{~min}$ in $0.05 \%$ diaminobenzidine in PBS with $0.03 \% \mathrm{H}_{2} \mathrm{O}_{2}$. The slides were counterstained with hematoxylin, dehydrated and mounted. The serial sections were routinely incubated with irrelevant mouse $\operatorname{IgG}$ at $4^{\circ} \mathrm{C}$ for $8 \mathrm{~h}$ as a negative control (Cat. no. NC494H; dilution 1:100; Biocare Medical, LLC, Paheco, CA, USA). A previously identified ovarian carcinoma sample was included as the positive control (17), and isotype control immunoglobulin $\mathrm{G}$ represents the negative control. Counterstaining was performed using hematoxylin and eosin for $3 \mathrm{~min}$ at room temperature. Slides were examined under a light microscope at x100 magnification in 3 fields of interest for each section, by two independent researchers blinded to the clinicopathological factors. The distribution of immunoreactivity for BECN1, LC3, or HMGB-1 was usually homogenous within a tumor and immunoreactivity was scored as follows: 0 (undetectable), $1+$ (weakly positive), $2+$ (moderately positive), and $3+$ (strongly positive). There were no significant differences of immunoreactivity scores between the two researchers. If 

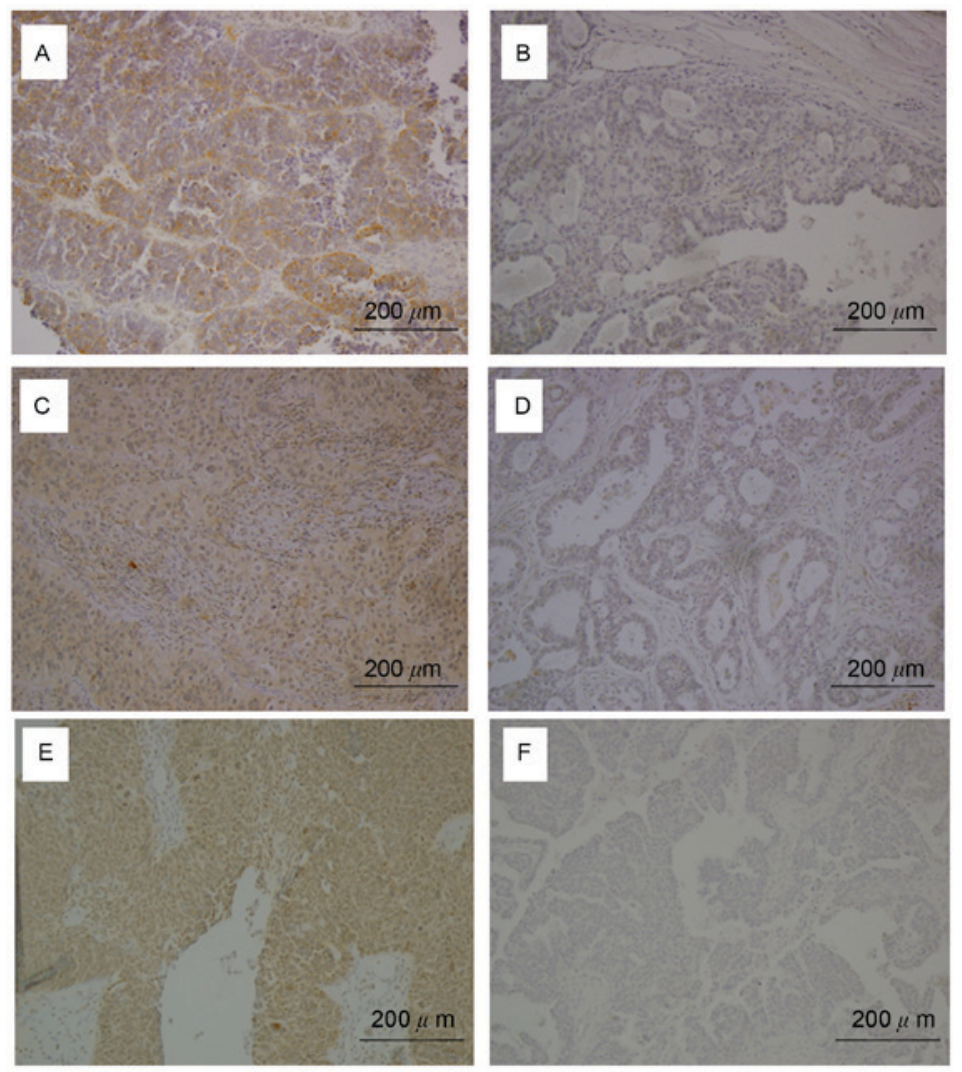

Figure 1. Immunohistochemical staining for BECN1, LC3, and HMGB-1 in ovarian carcinomas (A) Moderate to strong cytoplasmic BECN1 immunoreactivity. (B) Lack of beclin 1 expression. (C) Moderate to strong cytoplasmic LC3 immunoreactivity. (D) Lack of LC3 expression. (E) Strong cytoplasmic HMGB-1 immunoreactivity. (F) Lack of HMGB-1 expression. BECN1, beclin 1; LC3, 1A/1B-light chain 3; HMGB-1, high mobility group box-1 protein.

discrepancies occurred, a third investigator was assigned to score the tumor. The score to be assigned was determined by a majority vote. For analyses of clinicopathological factors and survival, patients with no expression were assigned to a negative expression group, while patients with weak, moderate, or strong expression were assigned to a positive expression group.

Statistical analysis. Progression-free survival and overall survival were calculated from the date of diagnosis to the date of first relapse or final follow up. Survival data were plotted on Kaplan-Meier curves and were compared using the log-rank test. Data were excluded when patients did not continue to follow-up. The chi-square test or Fisher's exact test were used for the comparison of categorical data. All analyses were conducted with the StatView statistical package, version 5.0 (Abacus Concepts, Piscataway, NJ, USA). Reported P-values were two-tailed and $\mathrm{P}<0.05$ was considered to indicate a statistically significant difference.

\section{Results}

Identification of BECN1, LC3, and HMGB-1 expression in ovarian tumors. BECN1, LC3, and HMGB-1 expression was examined by IHC (Fig. 1). Moderate to strong cytoplasmic expression of BECN1, LC3, and HMGB-1 was detected in ovarian carcinoma cells of at least $50 \%$ of patients (Fig. 1A, $\mathrm{C}, \mathrm{E}$, respectively), but was absent in other ovarian tumor sections (Fig. 1B, D, F). BECN1, LC3, and HMGB-1 were positively expressed in 58.2\% (82/141), $75.2 \%$ (106/141), and $53.2 \%$ (75/141) of ovarian tumor tissues, respectively.

Associations between the expression of autophagy-associated proteins and clinicopathological factors. BECN1 expression was significantly associated with the expression of LC3 $(\mathrm{P}<0.0001)$ and HMGB-1 $(\mathrm{P}<0.0001)$. However, there were no significant associations observed between BECN1, LC3, or HMGB-1 expression and any clinicopathological factors examined (Table I).

Associations of BECN1, LC3, and HMGB-1 with progression-free survival and overall survival in patients with ovarian cancer receiving platinum-taxane chemotherapy. Kaplan-Meier curves present estimates of progression free and overall survival in patients with ovarian carcinoma (Fig. 1). Loss of BECN1 expression was significantly associated with shorter progression-free survival and shorter overall survival $(\mathrm{P}=0.001$ and 0.017 , respectively; Fig. 2A and B). However, loss of LC3 or HMGB-1 expression was not associated with progression-free survival or overall survival (Fig. $2 \mathrm{C}-\mathrm{F}$ ). According to univariate analysis, FIGO stage III-IV ( $\mathrm{P}<0.0001$; log-rank test), high tumor grade $3(\mathrm{P}=0.033$; log-rank test), postoperative residual tumor $\geq 1 \mathrm{~cm}(\mathrm{P}<0.0001$; log-rank test $)$, and loss of BECN1 expression ( $\mathrm{P}=0.0006$; log-rank test) were significantly associated with shorter progression-free survival (Table II). Multivariate analysis revealed that postoperative residual tumor $\geq 1 \mathrm{~cm}(\mathrm{P}=0.002)$ and loss of BECN1 expression $(\mathrm{P}=0.046)$ were independently associated with shorter progression-free 
A

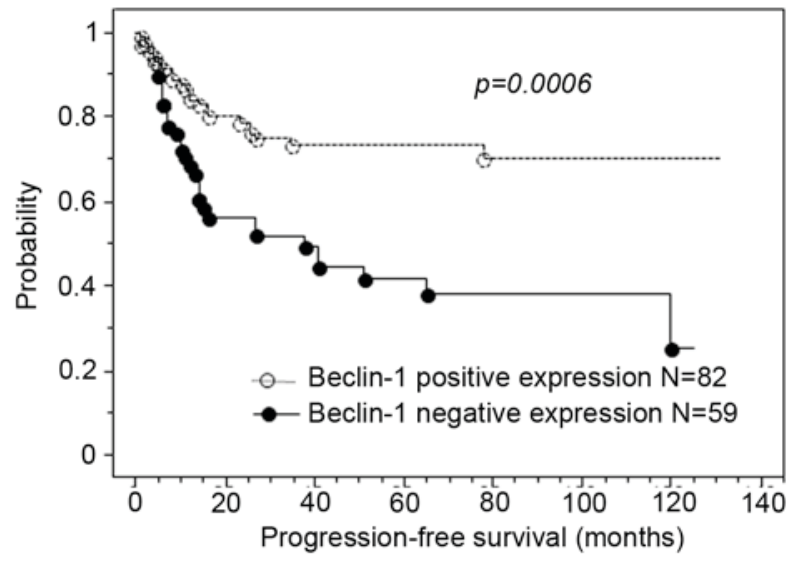

C

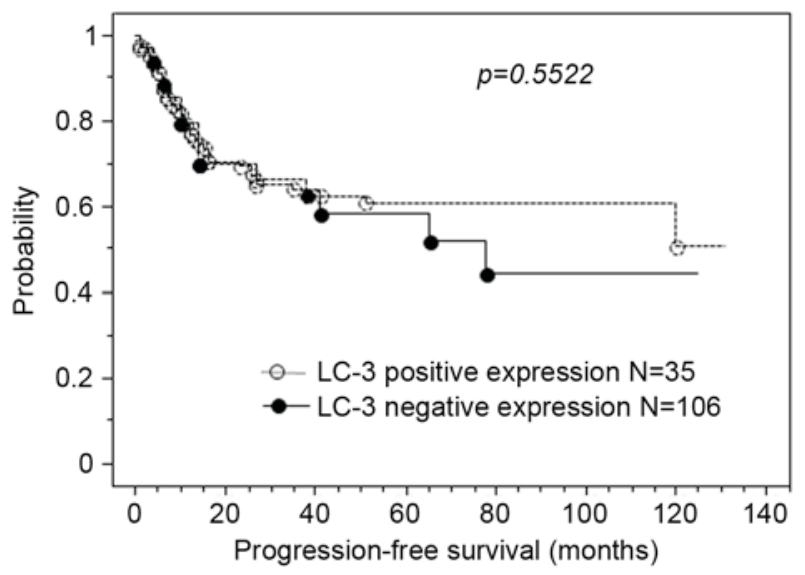

E

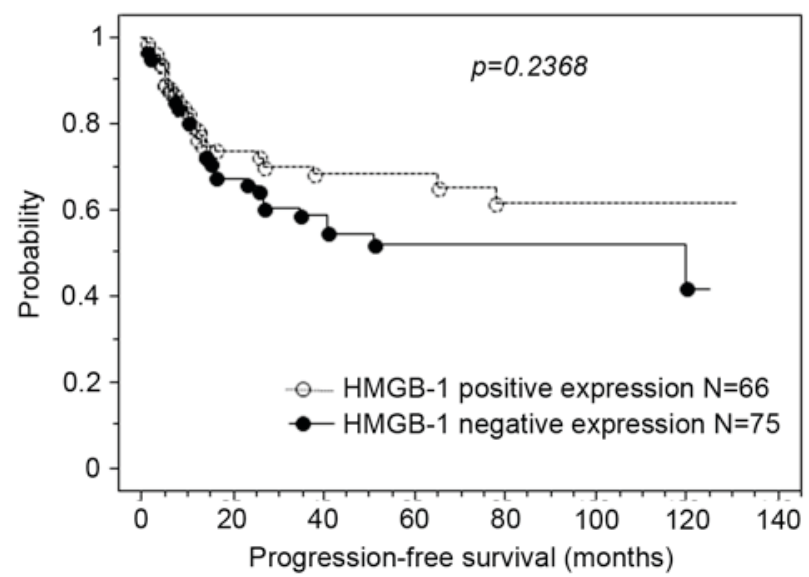

B

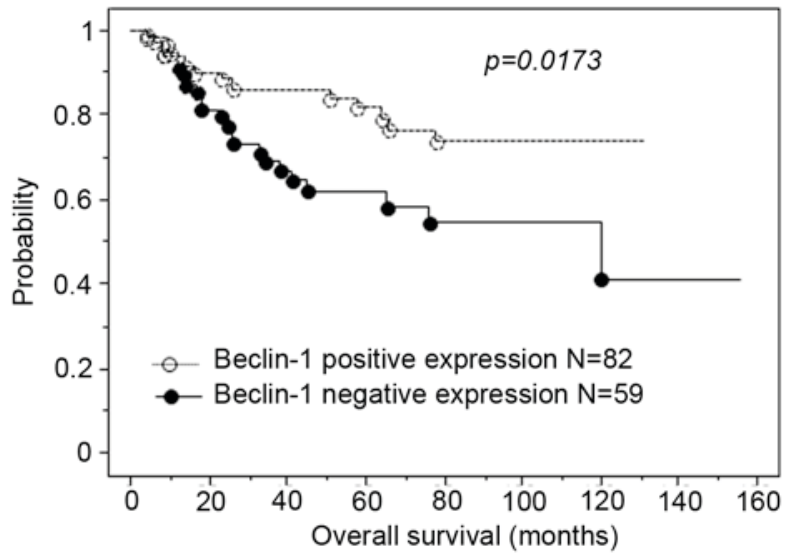

D

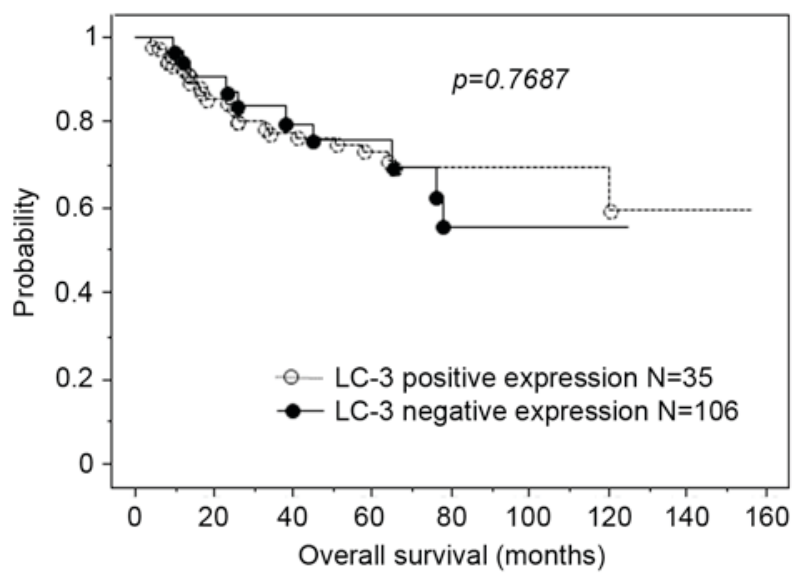

$\mathrm{F}$

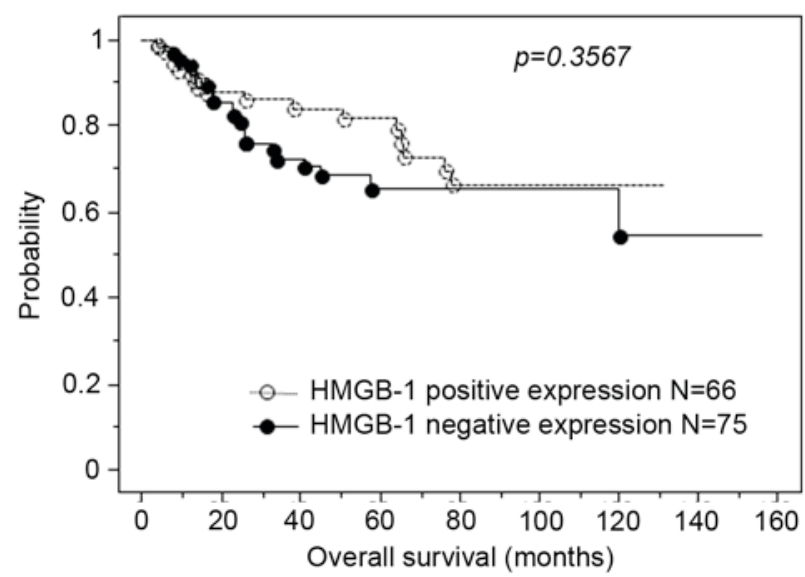

Figure 2. Kaplan-Meier survival analysis of patients with ovarian carcinoma undergoing primary cytoreductive surgery followed by standard platinum/taxane chemotherapy. Loss of BECN1 expression was associated with (A) shorter progression-free survival $(\mathrm{P}=0.0006)$ and $(\mathrm{B})$ shorter overall survival $(\mathrm{P}=0.0173$, log-rank test). Loss of LC3 expression was not associated with (C) progression-free survival ( $\mathrm{P}=0.5522)$ or $(\mathrm{D})$ overall survival ( $\mathrm{P}=0.7687)$. Loss of HMGB-1 expression was also not associated with (E) progression-free survival $(\mathrm{P}=0.2 .68)$ or $(\mathrm{F})$ overall survival $(\mathrm{P}=0.3567)$. BECN1, beclin 1; LC3, 1A/1B-light chain 3; HMGB-1, high mobility group box-1 protein.

survival (Table II). In addition, FIGO stage III-IV ( $\mathrm{P}<0.0001$; log-rank test), postoperative residual tumor $\geq 1 \mathrm{~cm}(\mathrm{P}<0.0001$; log-rank test), and loss of BECN1 expression ( $\mathrm{P}=0.017$; log-rank test) were revealed to be associated with overall survival by univariate analysis (Table III). Multivariate analysis confirmed that postoperative residual tumor $\geq 1 \mathrm{~cm}(\mathrm{P}=0.001)$ and loss of BECN1 expression $(\mathrm{P}=0.036)$ were independently associated with shorter overall survival (Table III).

\section{Discussion}

The present study demonstrated that the loss of BECN1 expression was an independent predictor of shorter progression-free survival and shorter overall survival in patients with ovarian carcinoma receiving platinum-taxane combination chemotherapy. Currently, there are limited available biomarkers that accurately predict early recurrence of ovarian 
Table II. Univariate and multivariate analyses of progression-free prognostic factors in patients with ovarian cancer.

\begin{tabular}{|c|c|c|c|c|c|c|c|}
\hline \multirow[b]{2}{*}{ Factors } & \multirow[b]{2}{*}{ Patients } & \multicolumn{3}{|c|}{ Univariate analysis } & \multicolumn{3}{|c|}{ Multivariate } \\
\hline & & Hazard ratio & $95 \% \mathrm{CI}$ & P-value ${ }^{a}$ & Hazard ratio & $95 \% \mathrm{CI}$ & P-value \\
\hline \multicolumn{8}{|c|}{ FIGO stage } \\
\hline III, IV & 61 & 3.8 & $2.1-6.8$ & $<0.0001^{\mathrm{a}}$ & 1.6 & $0.7-3.9$ & 1.594 \\
\hline I, II & 80 & & & & & & \\
\hline \multicolumn{8}{|l|}{ Grade } \\
\hline $\mathrm{G} 2, \mathrm{G} 3$ & 124 & 8.7 & $1.2-62.8$ & $0.0325^{\mathrm{a}}$ & 2.2 & $0.3-16.4$ & 0.4391 \\
\hline G1 & 16 & & & & & & \\
\hline \multicolumn{8}{|l|}{ Histology } \\
\hline Serous & 34 & 1.5 & $0.8-2.7$ & 0.1658 & NA & NA & NA \\
\hline Others & 107 & & & & & & \\
\hline \multicolumn{8}{|l|}{ Age, years } \\
\hline$\geqq 60$ & 59 & 1.7 & $1.0-2.9$ & 0.0576 & NA & NA & NA \\
\hline$<60$ & 82 & & & & & & \\
\hline \multicolumn{8}{|c|}{ Residual tumor, cm } \\
\hline$\geqq 1$ & 55 & 11.7 & $4.4-30.8$ & $<0.0001^{\mathrm{a}}$ & 3.9 & $1.6-9.2$ & $0.0024^{\mathrm{a}}$ \\
\hline$<1$ & 86 & & & & & & \\
\hline \multicolumn{8}{|c|}{ BECN1 expression } \\
\hline Negative & 59 & 2.6 & $1.5-4.5$ & $0.0006^{\mathrm{a}}$ & 1.9 & $1.0-3.6$ & $0.0462^{\mathrm{a}}$ \\
\hline Positive & 82 & & & & & & \\
\hline \multicolumn{8}{|c|}{ LC3 expression } \\
\hline Negative & 35 & 1.2 & $0.7-2.2$ & 0.5522 & NA & NA & NA \\
\hline Positive & 106 & & & & & & \\
\hline \multicolumn{8}{|c|}{ HMGB-1 expression } \\
\hline Negative & 66 & 1.4 & $0.8-2.4$ & 0.2368 & NA & NA & NA \\
\hline Positive & 75 & & & & & & \\
\hline
\end{tabular}

aP $<0.05$. CI, confidence interval; BECN1, beclin1; FIGO, International Federation of Gynecology and Obstetrics; LC3, 1A/1B-light chain 3; HMGB-1, high mobility group box -1 protein.

carcinoma $(18,19)$. Loss of BECN1 expression may potentially be used alone or in combination with other biomarkers to identify patients with ovarian carcinoma, who demonstrate an increased susceptibility to early disease recurrence. This is clinically relevant given that $\sim 60 \%$ of patients with advanced ovarian carcinoma who demonstrate a complete response to primary therapy, will develop recurrence (20). Potentially, the assessment of BECN1 may have an impact on disease management. Patients with recurrent ovarian carcinoma gain the greatest benefit from secondary cytoreductive therapy if the recurrent tumors remain small and localized (20-24). Therefore, an increased frequency of follow-up in patients with loss of BECN1, to detect recurrence earlier, may allow patients to quickly receive further beneficial cytoreductive surgery or second-line chemotherapy.

Multiple previous studies have demonstrated comparable data in line with the present study, in that the loss of BECN1 was reported to be associated with an unfavorable prognosis of several solid cancers, including ovarian carcinoma $(15,25-27)$. In contrast, other studies demonstrated that the loss of BECN1 was significantly correlated with improved survival in patients with endometrial cancer, renal cell cancer, and colorectal cancer (28-30). These differences may be due to a lack of consistency between studies and/or variations in methodologies, or may be disease-specific. The variations in methodologies between studies, including the specific antibody and dilution used, and/or the method for assessing immunohistochemical staining, may lead to significant variability in results. Furthermore, several studies, the present one included, had relatively small sample sizes, and larger prospective studies are required to definitively determine the association of BECN1 expression with the prognosis of ovarian cancer. Finally, discrepancies between studies may be associated with tissue-specific differences of oncogenic pathways, and therefore tissue-specific differences in the loss of BECN1 expression require further investigation.

The present study demonstrated a strong association between a poor prognosis and loss of BECN1 expression in patients with ovarian carcinoma receiving platinum-taxane chemotherapy. Although the expression of BECN1 was associated with LC3 and HMGB-1 expression, expression of the latter two proteins was not associated with poor survival. Given that all three proteins are involved in processes of autophagy, this was an unexpected discovery. It is thus speculated that the 
Table III. Univariate and multivariate analysis of overall prognostic factors in patients with ovarian cancer.

\begin{tabular}{|c|c|c|c|c|c|c|c|}
\hline \multirow[b]{2}{*}{ Factors } & \multirow[b]{2}{*}{ Patients } & \multicolumn{3}{|c|}{ Univariate analysis } & \multicolumn{3}{|c|}{ Multivariate analysis } \\
\hline & & Hazard ratio & $95 \%$ CI & P-value ${ }^{a}$ & Hazard ratio & $95 \% \mathrm{CI}$ & P-value \\
\hline \multicolumn{8}{|c|}{ FIGO stage } \\
\hline III, IV & 61 & 3.8 & $2.1-6.8$ & $0.0001^{\mathrm{a}}$ & 2 & $0.8-5.1$ & 0.122 \\
\hline I, II & 80 & & & & & & \\
\hline \multicolumn{8}{|l|}{ Grade } \\
\hline $\mathrm{G} 2, \mathrm{G} 3$ & 124 & 5.3 & $0.7-38.5$ & 0.1011 & NA & NA & NA \\
\hline G1 & 16 & & & & & & \\
\hline \multicolumn{8}{|l|}{ Histology } \\
\hline Serous & 34 & 1.5 & $0.8-2.7$ & 0.1658 & NA & NA & NA \\
\hline Others & 107 & & & & & & \\
\hline \multicolumn{8}{|l|}{ Age, years } \\
\hline$\geqq 60$ & 59 & 1.7 & $1.0-2.9$ & 0.0576 & NA & NA & NA \\
\hline$<60$ & 82 & & & & & & \\
\hline \multicolumn{8}{|c|}{ Residual tumor, cm } \\
\hline$\geqq 1$ & 55 & 11.7 & $4.4-30.8$ & $<0.0001^{\mathrm{a}}$ & 4.4 & $1.8-11.0$ & $0.0013^{\mathrm{a}}$ \\
\hline$<1$ & 86 & & & & & & \\
\hline \multicolumn{8}{|c|}{ BECN1 expression } \\
\hline Negative & 59 & 2.2 & $1.1-4.2$ & 0.0173 & 2 & $1.0-3.8$ & $0.0364^{\mathrm{a}}$ \\
\hline Positive & 82 & & & & & & \\
\hline \multicolumn{8}{|c|}{ LC-3 expression } \\
\hline Negative & 35 & 1.1 & $0.7-2.3$ & 0.7687 & NA & NA & NA \\
\hline Positive & 106 & & & & & & \\
\hline \multicolumn{8}{|c|}{ HMGB-1 expression } \\
\hline Negative & 66 & 1.4 & $0.7-2.6$ & 0.3567 & NA & NA & NA \\
\hline Positive & 75 & & & & & & \\
\hline
\end{tabular}

${ }^{\mathrm{a}} \mathrm{P}<0.05$. CI, confidence interval; BECN1, beclin1; FIGO, International Federation of Gynecology and Obstetrics; LC3, 1A/1B-light chain 3; HMGB-1, high mobility group box -1 protein.

association between the loss of BECN1 and poor survival may be associated with a function of BECN1 outside its involvement in autophagy. In a previous study, Rohatgi et al (31) reported that BECN1 regulates growth factor signaling, including the protein kinase B (AKT) and extra-cellular signal-regulated kinase (ERK) pathways. Therefore, reduction of BECN1 expression may cause dysregulation of growth factor receptor signaling, leading to tumor progression (31). This is indicative of an autophagy-independent function for BECN1 in ovarian cancer. Furthermore, our previous study revealed that BECN1 involvement in autophagy was not associated with resistance of ovarian clear cell carcinoma to platinum agents (17). Thus, the results from the present study, and from previous studies indicated that enhanced growth factor signaling due to the loss of BECN1 may be a novel mechanism that explains treatment failure in patients with loss of BECN1 expression.

The mechanisms underlying the association between the loss of BECN1 expression and shorter survival in patients with ovarian carcinoma are unknown. However, mortality in patients with ovarian cancer is directly associated with disease recurrence following chemotherapy. It is therefore hypothesized that the loss of BECN1 expression confers chemoresistance and/or enhances cell proliferation in recurrent tumors (17). The present study identified previously unknown patterns of BECN1 expression in ovarian carcinoma, and further investigation is warranted to elucidate the associations between the loss of BECN1 expression and tumor sensitivity to other chemotherapy drugs including paclitaxel, a key agent for ovarian cancer.

To conclude, loss of BECN1 protein expression was revealed to be an independent marker for poor progression-free survival and poor overall survival in patients with ovarian carcinoma receiving platinum-taxane chemotherapy.

\section{Acknowledgements}

The present study was supported by grants from the Ministry of Education, Culture, Sports, Science and Technology in Japan (grant no. 15K10717). 


\section{References}

1. Allemani C, Weir HK, Carreira H, Harewood R, Spika D, Wang XS, Bannon F, Ahn JV, Johnson CJ, Bonaventure A, et al: Global surveillance cancer survival 1995-2009: Analysis of individual data for $25,676,887$ patients from 279 population-based registries in 67 countries (CONCORD-2). Lancet 385: 977-1010, 2015.

2. American Cancer Sosiety: Cancer Facts and Figures 2017. Atlanta, Ga, American Cancer Society, 2017.

3. Pfisterer J and Ledermann JA: Management of platinum-sensitive recurrent ovarian cancer. Semin Oncol 33 (2 Suppl 6): S12-S16, 2006.

4. Nakayama K, Nakayama N and Miyazaki K: Development of a novel ovarian cancer molecular target therapy against cancer related transcriptional factor, NAC1. J Obstet Gynaecol Res 39: 18-25, 2013.

5. Agarwal R, Linch M and Kaye SB: Novel therapeutic agents in ovarian cancer. Eur J Surg Oncol (EJSO) 32: 875-886, 2006.

6. Hanahan D and Weinberg RA: The hallmarks of cancer. Cell 100: $57-70,2000$.

7. Shimizu S, Kanaseki T, Mizushima N, Mizuta $\mathrm{T}$, Arakawa-Kobayashi S, Thompson CB and Tsujimoto Y: Role of Bcl-2 family proteins in a non-apoptotic programmed cell death dependent on autophagy genes. Nat Cell Biol 6: 1221-1228, 2004

8. Rashmi R, Pillai SG, Vijayalingam S, Ryerse J and Chinnadurai G: $\mathrm{BH} 3-$ only protein BIK induces caspase-independent cell death with autophagic features in Bcl-2 null cells. Oncogene 27: 1366-1375, 2008.

9. Furuya D, Tsuji N, Yagihashi A and Watanabe N: Beclin 1 augmented cis-diamminedichloroplatinum induced apoptosis via enhancing caspase-9 activity. Exp Cell Res 307: 26-40, 2005

10. Sun Y, Liu JH, Jin L, Pan L, Sui YX, Yang Y and Shi H: Beclin 1 influences cisplatin-induced apoptosis in cervical cancer CaSki cells by mitochondrial dependent pathway. Int J Gynecol Cancer 22: 1118-1124, 2012.

11. Wang J: Beclin 1 bridges autophagy, apoptosis and differentiation. Autophagy 4: 947-948, 2008.

12. Eskelinen EL and Saftig P: Autophagy: A lysosomal degradation pathway with a central role in health and disease. Biochim Biophys Acta 1793: 664-673, 2009.

13. Mizushima N: Methods for monitoring autophagy. Int J Biochem Cell Biol 36: 2491-2502, 2004.

14. Tang D, Kang R, Cheh CW, Livesey KM, Liang X, Schapiro NE, Benschop R, Sparvero LJ, Amoscato AA, Tracey KJ, et al: HMGB1 release and redox regulates autophagy and apoptosis in cancer cells. Oncogene 29: 5299-5310, 2010.

15. Cai M, Hu Z, Liu J, Gao J, Liu C, Liu D, Tan M, Zhang D and Lin B: Beclin 1 expressin in ovarian tissues and its effect on ovarian cancer prognosis. Int Mol Sci 15: 5292-5303, 2014.

16. Odicino F, Pecorelli S, Zigliaani L and Creasman WT: History of the FIGO cancer staging system. Int J Gyneacol Obstet 101: 205-210, 2008

17. Katagiri H, Nakayama K, Razia S, Nakamura K, Sato E, Ishibashi T, Ishikawa M, Iida K, Ishikawa N, Otsuki Y, et al: Loss of autophagy-related protein Beclin 1 may define poor prognosis in ovarian clear cell carcinomas. Int J Oncol 47: 2037-2044, 2015.
18. Katagiri A, Nakayama K, Rahman MT, Rahman M, Katagiri H, Nakayama N, Ishikawa M, Ishibashi T, Iida K, Kobayashi H, et al: Loss of ARID1A expression is related to shorter progression-free survival and chemoresistance in ovarian clear cell carcinoma Mod Pathol 25: 282-288, 2012.

19. Nakayama K, Rahman MT, Rahman M, Yeasmin S, Ishikawa M, Katagiri A, Iida K, Nakayama N and Miyazaki K: Biological role and prognostic significance of $\mathrm{NACl}$ in ovarian cancer. Gynecol Oncol 119: 469-478, 2010

20. Díaz-Montes TP and Bristow RE: Secondary cytoreduction for patients with recurrent ovarian cancer. Curr Oncol Rep 7: 451-458, 2005.

21. Harter P and du Bois A: The role of surgery in ovarian cancer with special emphasis on cytoreductive surgery for recurrence. Curr Opin Oncol 17: 505-514, 2005.

22. Gadducci A, Iacconi P, Cosio S, Fanucchi A, Cristofani R and Riccardo Genazzani A: Complete salvage surgical cytoreduction improves further survival of patients with late recurrent ovarian cancer. Gynecol Oncol 79: 344-349, 2000

23. Gadducci A, Iacconi P, Fanucchi A, Cosio S, Teti G and Genazzani AR: Surgical cytoreduction during second-look laparotomy in patients with advanced ovarian cancer. Anticancer Res 20: 1959-1964, 2000.

24. Zang RY, Li ZT, Tang J, Cheng X, Cai SM, Zhang ZY and Teng NN: Secondary cytoreductive surgery for patients with relapsed epithelial ovarian carcinoma: Who benefits? Cancer 100: 1152-1161, 2004.

25. Lin HX, Qiu HJ, Zeng F, Rao HL, Yang GF, Kung HF, Zhu XF, Zeng YX, Cai MY and Xie D: Decreased expression of Beclin 1 correlates closely with $\mathrm{Bcl}-\mathrm{xL}$ expression and poor prognosis of ovarian carcinoma. PLoS One 8: e60516, 2013.

26. Zhou WH, Tang F, Xu J, Wu X, Yang SB, Feng ZY, Ding YG, Wan XB, Guan Z, Li HG, et al: Low expression of Beclin 1, associated with high $\mathrm{Bcl}-\mathrm{xL}$, predicts a malignant phenotype and poor prognosis of gastric cancer. Autophagy 8: 389-400, 2012.

27. Qiu DM, Wang GL, Chen L, Xu YY, He S, Cao XL, Qin J, Zhou JM, Zhang YX and E Q: The expression of beclin-1, an autophagic gene, in hepatocellular carcinoma associated with clinical pathological and prognostic significance. BMC Cancer 14: 327, 2014.

28. Giatromanolaki A, Koukourakis MI, Koutsopoulos A, Chloropoulou P, Liberis V and Sivridis E: High Beclin 1 expression defines a poor prognosis in endometrial adenocarcinomas. Gynecol Oncol 123: 147-151, 2011.

29. Nishikawa M, Miyake H, Liu B and Fujisawa M: Expression pattern of autophagy-related markers in non-metastatic clear cell renal cell carcinoma: Association with disease recurrence following radical nephrectomy. J Cancer Res Clin Oncol 141: $1585-1591,2015$

30. Han Y, Xue XF, Shen HG, Guo XB, Wang X, Yuan B, Guo XP, Kuang YT, Zhi QM and Zhao H: Prognostic significance of Beclin-1 expression in colorectal cancer: A meta-analysis. Asian Pac J Cancer Prev 15: 4583-4587, 2014.

31. Rohatgi RA, Janusis J, Leonard D, Bellvé KD, Fogarty KE, Baehrecke EH, Corvera S and Shaw LM: Beclin 1 regulates growth factor receptor signaling in breast cancer. Oncogene 34: $5352-5362,2015$ 